Final version in Erkenntnis, 2021. DOI: 10.1007/s10670-020-00362-w

\title{
Linguistic understanding and testimonial warrant
}

\begin{abstract}
How much linguistic understanding is required for testimonial knowledge acquisition? One answer is that, so long as we grasp the content expressed by the speaker, it does not matter if our understanding of it is poor. Call this the 'Liberal View' of testimony. This approach looks especially promising when combined with the thesis that we share a public language that makes it easy to grasp the right content. In this paper, I argue that this picture is epistemically problematic. Poor linguistic understanding undermines our ability to recognise evidence and counterevidence for the testimonial content. Because of this, in many cases in which a hearer's understanding is poor, her resultant testimonial belief will lack sufficient warrant to qualify as knowledge. Given that we often do not possess a sufficiently good understanding of the testimony we consume, I argue that we acquire far less knowledge through testimony than the Liberal View suggests.
\end{abstract}

\section{Introduction}

Consider some technical fact from a discipline with which you are relatively unfamiliar. Perhaps you learnt that Gödel proved the incompleteness of arithmetic from reading Kripke, but you have little idea what incompleteness is. Or, perhaps, through catching a snippet of a radio show, you learnt that Peter Maxwell Davies used magic squares, but you have no idea who Maxwell Davies is or what a magic square might be. We have plenty of these kinds of fact stored in our memories, but could they amount to knowledge? What I will call the 'Liberal View' of testimony claims that they can: that is, we can gain testimonial knowledge with content that we incompletely understand. There are authors, such as Goldberg (2007) and Adler (1996), who explicitly endorse Liberal Views of testimony. As I will go on to explain in Section 2, there is reason to think that a great many epistemologists who work on testimony are also committed to it, even if they do not explicitly avow this commitment. In contrast, more conservative 
approaches to testimony would claim that a high degree of linguistic understanding is a necessary condition on testimonial knowledge acquisition; however, in the literature, the reasons for adopting this latter view of the connection between linguistic understanding and testimonial knowledge have not been well explored.

In this paper, I have two related aims. The first is to argue for a particular view of the relationship between linguistic understanding and testimonial warrant. I will argue that testimonial warrant is heavily dependent on (a certain kind of) linguistic understanding such that, if a hearer fails to understand the speaker's testimony, her warrant for accepting this testimony will be thereby diminished. My second aim is to argue that, given this first result, there is reason to think that the Liberal View is false: testimonial knowledge often requires a significant degree of correct linguistic understanding. If successful, one consequence of my argument is that we gain far less knowledge through testimony than is popularly thought. This is a significant departure from how we have thus far viewed testimony as a source of knowledge. It is typically treated as a constraint on a good theory of testimony that it can claim that testimonial knowledge is relatively easily and often acquired. Given the foundational role that this constraint is often afforded in the literature, I think it is important to more carefully investigate whether it is ultimately defensible. This paper contributes towards this end by exploring one reason for thinking that the constraint is problematic.

The paper proceeds as follows. In Sections 1 and 2, I begin with some preliminary remarks concerning testimony and linguistic understanding and set out the Liberal View. In Section 3, I argue for the dependence of testimonial warrant on linguistic understanding. In Section 4, I demonstrate why we should think that knowledge through testimony is harder to acquire than the Liberal View maintains. 
A testimony-based belief is a belief that a hearer forms by accepting the content she recovers through the speaker's testimony. ${ }^{1}$ This testimony-based belief will qualify as knowledge when the speaker accepts this content under certain epistemic and semantic conditions. The job of a theory of testimonial knowledge acquisition is to tell us what these conditions are. In this section, I explain which elements of these conditions are relevant to my argument and identify some assumptions.

With respect to the epistemic conditions on testimonial knowledge acquisition, I hope to remain largely neutral between prominent views in the testimony literature. I will argue that poor linguistic understanding will undermine an agent's warrant for accepting testimony by rendering her insensitive to evidence and counterevidence and, thus, an unreliable consumer of testimony. My argument will confront any view that includes a 'no defeaters' condition on testimonial knowledge (/warrant): ${ }^{2}$

No Defeaters Condition: A hearer, $\mathrm{H}$, can gain knowledge (/knowledge-sufficient warrant) through a speaker, S's, testimony only if H lacks undefeated defeaters for S's testimony.

Roughly speaking, a defeater is something that (if left undefeated) removes, diminishes, or prevents warrant for some target belief. There are different kinds of defeater; the ones primarily relevant to my argument are doxastic defeaters. Doxastic defeaters are mental states of the subject - they undermine warrant for a target belief in virtue of the inferential relationships that they stand in to this target belief or to the further beliefs that support it (see, e.g., Lackey 2005,

\footnotetext{
${ }^{1}$ Knowledge through testimony is sometimes distinguished from mere knowledge from testimony. Knowledge through testimony is knowledge that is gained through accepting the content that one recovers from the exchange. Knowledge from testimony is any other knowledge that one might gain as a result of observing the testimonial exchange - such as, for example, that the speaker has a soprano voice. (See Goldberg 2007, Audi 1997).

${ }^{2}$ Depending on one's view of defeaters, the problem will be that subjects with poor understanding of a testimonial content are rendered either (a) less capable of recognising defeaters or (b) less capable of possessing them.
} 
Bergmann 2005). ${ }^{3}$ I will treat warrant as a more general property of which justification and entitlement are species (internalist and externalist species, respectively). ${ }^{4}$ Views in the epistemology of testimony typically appeal to some form of warrant as a necessary condition on testimonial knowledge acquisition alongside true belief. In addition, I am treating warrant as something that admits of degrees such that a belief can enjoy some degree of warrant without possessing a level of warrant sufficient for knowledge. 'Knowledge-sufficient warrant' is whatever factor (or factors) transforms a true testimonial belief into knowledge. Treating things this way will be important later, as I will be arguing both that poor linguistic understanding undermines (that is, lowers) warrant and that it often undermines warrant to a level below the threshold for knowledge.

What of the semantic conditions on testimonial knowledge acquisition? When a speaker testifies that $p$, must the hearer grasp $p$ itself - must content be 'preserved' across the exchange - or would grasp of some merely similar content, $p^{*}$, be sufficient for testimonial success? For the purposes of this paper, I will proceed on the assumption that, in paradigmatic cases at least, content preservation is required for testimonial knowledge acquisition (Goldberg 2007, Fricker 2006, Burge 1993). ${ }^{5}$ However, this assumption is merely for ease of exposition. I don't believe that my conclusion is true of only those views of testimony that require content preservation. Rather, a version of my argument would also apply to those who think that hearers can (and often do) gain knowledge that $p$ from testimony that $p^{*}$; but the reasons for this are different from those I present in this paper.

A commitment to content preservation will place certain constraints on the kind of foundational semantic theory that can underwrite a theory of testimonial knowledge acquisition. If, as most believe, a large number of our testimony-based beliefs qualify as knowledge, then we need an account of meaning and thought content that can claim that content preservation is both possible

\footnotetext{
${ }^{3}$ There are different ways in which a defeater can defeat a target belief. See Pollock (1986).

${ }^{4}$ See, e.g., Burge (2003), Gerken (2013), Graham (2016).

${ }^{5}$ For a view that does not require content preservation, see Peet (2019). See also Fricker $(2012, \mathrm{fn} .8)$.
} 
and at least as widespread as would be required to underpin the success of our testimonial exchanges. It is a controversial issue which views this will rule out. ${ }^{6}$ However, there are certain views which appear well placed to secure widespread content preservation. Social externalism about mental content, for example, claims that the content of our thoughts and utterances is individuated, in part, by our external social environment (Goldberg 2007, Brown 2004, Burge 1979). Social externalists claim that speakers within a language community share many of their concepts; as I will explain further in Sect. 2, this arguably makes it easy for a hearer to grasp the same content as that which is expressed in the speaker's testimony (at least, in comparison with theories that do not posit shared content). For the purposes of this paper, I assume that social externalism is true. I do this for two reasons. Firstly, it is the view endorsed by Goldberg (2007), who is the most prominent defender of the Liberal View. Secondly, it is generally very popular and thus will provide a familiar framework within which to pose my argument. However, as with the content preservation assumption, I stress that my argument is not intended to pose a special problem for social externalism over other views of content individuation - the assumption is merely for ease of exposition.

There are certain features of social externalism that will be important to my argument. The view must allow that a subject can form beliefs with contents that she does not fully understand. The view allows this because the conditions on concept possession are quite undemanding. A subject should be attributed a concept that is shared with the rest of her community provided that she demonstrates a basic linguistic competence with respect to her language in general (or relevant parts of it), and that she is disposed to accept correction from expert language users with respect to the correct application of the concept (Burge 1979: 114). These conditions do not require of a subject that she understands the concepts that she entertains very well at all, although social externalists may include some minimal constraints on the extent to which a subject can fail to understand the contents of her own thoughts - Burge, for example, tentatively

\footnotetext{
${ }^{6}$ Goldberg (2007), for example, argues that internalist views cannot claim that there is widespread content preservation.
} 
suggests that we might wish to refrain from attributing to a subject the belief that he has been drinking orangutans for breakfast (1979: 90-1). Burge calls the phenomenon whereby a subject can grasp a concept without understanding it 'partial grasp' or 'incomplete understanding'. This incomplete understanding might involve false beliefs about the application of a concept or the object represented (as when one thinks that an orangutan is a kind of fruit drink), although it can also be that the subject is simply agnostic about how to apply a concept or term (as when one has heard the word 'orangutan' but has few beliefs about what sort of object it might be).

Social externalism, then, allows that we can form beliefs that we incompletely understand. Some of these beliefs will be testimony-based beliefs. The central question that I am interested in in this paper is this: can our testimony-based beliefs enjoy a high degree of warrant even when their contents are poorly understood? In the next section, I introduce two broad approaches to answering this question.

\section{$2 \quad$ Linguistic understanding}

Any theory of testimonial knowledge acquisition ought to claim that a hearer must understand the content of the testimony proffered in one sense or another. It would be implausible to allow, for example, that a hearer can gain knowledge that $p$ through testimony expressed in a language that she does not speak. However, there are different options for theories of linguistic understanding that might be plugged into one's account of testimonial knowledge (/warrant). The kind of understanding relevant to my argument is what I will call inferential understanding'. On this approach, correct understanding requires that a hearer be largely correct in her interpretation of the speaker's utterance in the following sense: she must have a good grasp of the inferential relations that hold between the testimonial content and the rest of her beliefs. For example, if a subject is to correctly understand that her job interview is in a fortnight, she must also believe that a fortnight is 14 days long, and that a day is a period of 24 hours, etc., such that inferences made from her new testimonial belief will be largely correct. On 
this account, to say that one does not understand an assertion in a foreign language is to say that one does not grasp its inferential connections to the rest of one's network of beliefs. Inferential understanding could be included in a condition on testimonial knowledge acquisition in varying strengths. Here is a strong version of the requirement:

Strong Inferential Understanding Requirement: For a hearer to gain knowledge from testimony, it is necessary that she possess a high level of inferential understanding of the content of the speaker's testimony.

Against the backdrop of our earlier assumptions, the idea here is that, while subjects may gain beliefs that they incompletely understand, a belief cannot amount to knowledge unless it is reasonably well (inferentially) understood. Even if one does not include inferential understanding in a necessary condition on knowledge, however, one may nonetheless think that testimonial warrant depends on inferential understanding:

Inferential Understanding Dependency: If a hearer incompletely understands the testimonial content, her warrant for accepting a speaker's testimony will be undermined. $^{7}$

I use 'incomplete' understanding in the Burgean sense introduced earlier - that is, incomplete understanding covers both cases in which the hearer understands the testimonial content incorrectly, and cases in which she is simply agnostic with respect to its inferential connections to the rest of her beliefs. ${ }^{8}$

In this paper, I am primarily interested in arguing for Inferential Understanding Dependency - I argue for this in Sect. 3. However, I will, in Sect. 4, argue that testimony-based beliefs that are

\footnotetext{
${ }^{7}$ One could also frame this thesis in terms of degrees of understanding: To the degree that a hearer incompletely understands the testimonial content, her warrant for accepting a speaker's testimony will be undermined.

${ }^{8}$ I use the terms 'incomplete understanding' and 'poor understanding' interchangeably.
} 
incompletely understood will often (if not always) lack sufficient warrant to qualify as knowledge. In arguing this, I will be arguing against the Liberal View of testimony. In the remainder of this section, I set out this view in more detail.

The Liberal View is not a complete view of the conditions on testimonial knowledge acquisition. Rather, it is a view specifically about the connection between testimonial knowledge acquisition and inferential linguistic understanding. As such, Liberalism should be seen as one axis along which we can divide theories of testimony. The central claim of the Liberal View is that testimonial knowledge acquisition (always or often) requires only a low level of inferential understanding: subjects can gain testimonial knowledge that they (inferentially) incompletely understand. Note that claiming this requires denying the Strong Inferential Understanding Requirement, but it does not require denying Inferential Understanding Dependency. It might be that testimonial warrant does depend on inferential understanding, but that testimony-based beliefs enjoy additional sources of warrant that offset the warrant-undermining effects of incomplete understanding. The Liberal View claims that a high degree of inferential understanding is not (or not often) required for testimonial knowledge acquisition, not that it is irrelevant to warrant.

Defenders of the Liberal View have, however, foreground an alternative conception of linguistic understanding in their accounts of testimony. Goldberg (2007) offers the most developed version of a Liberal View in the literature. He argues that the understanding involved in acquisition of testimonial knowledge is of a kind which is not tied to a subject's inferential competence with the testimonial content. ${ }^{9}$ Following Goldberg, I will call this kind of understanding 'reliable comprehension'. On this account, a subject may be said to 'correctly' understand an utterance even when her inferential understanding of its content is quite incorrect (Goldberg 2007: 124-5). The reason for this is that, on Goldberg's account, an act of utterance understanding simply involves the hearer mapping the content of the speaker's utterance onto

\footnotetext{
${ }^{9}$ For an overview of further approaches to linguistic understanding, see Longworth (2010).
} 
the appropriate item of mental content in the hearer's own conceptual repertoire; understanding is successful if this mapping is correct and reliably attained. To require reliable comprehension is, thus, just to require (reliable) content preservation.

This account depends on Goldberg's social externalism about mental content. For the social externalist, to correctly recover the content of the concepts expressed by the lexical items apparent from the surface form of an utterance, a generally competent language user simply needs the disposition to defer to her community with respect to these concepts. On Goldberg's (2007: 79ff) approach, a hearer's comprehension is settled by the existence of public linguistic norms that govern content assignments in accordance with the public language. Social externalists can allow that subjects recover shared concepts even when they have not previously encountered them. ${ }^{10}$ To return to our example from earlier, a subject may correctly recover the content of the concept 'magic square', even if she did not previously possess this concept: when she encounters a new expression, a new entry will be generated in her mental lexicon, with its content secured by her dispositions to defer to her language community. ${ }^{11}$ Social externalism does not guarantee that one grasps the content that the speaker expressed. When encountering a new expression, even a very permissive social externalist will likely maintain that the subject must acquire a minimal understanding of its meaning. This kind of understanding can often be grasped from the context in which the word is acquired (cf. Hudson 2007: 52ff). For example, suppose an agent encounters the word 'brisket' for the first time when her friend tells her 'We are having brisket for dinner'. In this case, the subject can tell from the context that 'brisket' is a noun; moreover, she can discern that it represents a particular kind of object - a food. Alternatively, even when one recovers the concepts evident from the surface form of the speaker's utterance, communication may still fail if one recovers the wrong explicature. However, although there are ways that communication can breakdown, social externalism does make content recovery relatively easy. On Goldberg's view, subjects can reliably comprehend

\footnotetext{
${ }^{10}$ Thank you to anonymous reviewer for suggesting this clarification.

${ }^{11}$ Kripke (1980), of course, makes a similar point about our use of previously unfamiliar names.
} 
each other despite quite serious differences and mistakes in their inferential understanding of the content communicated. He writes,

\begin{abstract}
A hearer can count as having 'understood' testimony in the required sense even when she does not completely grasp all of the concepts in the attested content (and even when she has a non-standard theory of the subject-matter in question). (2007: 104)
\end{abstract}

This approach might seem strange - for it claims that a subject can understand the utterance of her interlocutor correctly even though she possesses a large number of misconceptions as to its representational and inferential properties. However, strange or not, Liberal Views like Goldberg's enjoy strong motivation from the desire for an approach to testimony that can allow that a great many of our testimonial exchanges are successful. Goldberg claims that, whatever theory of linguistic understanding one includes in one's account of testimonial knowledge acquisition, it must be one that can allow for the widespread success of testimonial exchanges. He writes:

I submit that the testimonial spread of knowledge places an important constraint on theories of linguistic understanding: it should turn out that the linguistic understanding of the typical subject is such that she typically does attain a state of reliable comprehension of what she is told without further ado. (Goldberg 2007: 46)

This starting point is why Goldberg comes to endorse reliable comprehension over something like the Strong Inferential Understanding Requirement: the latter, being more demanding, will land us with a considerably more sceptical view of the success rate of our testimonial exchanges. Those of us who lack the relevant understanding would not know that Gödel proved the incompleteness of arithmetic, or that Maxwell Davies composed using magic squares, etc. ${ }^{12}$

\footnotetext{
${ }^{12}$ Epistemologists sometimes use scientific claims in examples of knowledge through testimony. Goldberg (2007: 73), for example, uses the example 'Electrons have spin.' While we surely do gain some
} 
We would even lack various items of more garden-variety knowledge in cases in which our understanding happens to be poor. You might not come to know, for example, that your friend is making brisket for dinner or that your aunt plays the dulcimer. The Liberal View, then (against the backdrop of social externalism), offers us a neat and appealing picture of the role of understanding (comprehension) in the acquisition of testimonial knowledge.

Just as there are different strengths of inferential understanding requirement, so too are there different strengths of testimonial Liberalism. I take it that Goldberg represents the more radical end of the spectrum. He thinks that a theory of testimonial knowledge acquisition need only appeal to reliable comprehension. ${ }^{13}$ Goldberg also cites Adler as a defender of this kind of view:

Knowledge obtained purely by transmission or testimony is 'thin.' [...] The seeker need not even understand p. There are many who know from the testimony of others something to the effect that "Gödel's Theory proves arithmetic incomplete" without grasping the rudiments of either the proof or the technical meaning of the crucial terms e.g. 'incomplete.' (Adler 1996: 107, quoted in Goldberg 2007: 38-39)

How prevalent is the Liberal View among epistemologists? A commitment to this approach is not often explicitly avowed by authors. As Goldberg (2007: 54) notes, epistemologists have not paid very much attention to the role of linguistic understanding in testimonial knowledge acquisition. ${ }^{14}$ Authors typically restrict their focus to cases in which it is stipulated that the hearer grasps the content of the speaker's assertion, but they do not specify whether they think that there is more to linguistic understanding than content preservation and so it is unclear

scientific knowledge through testimony, many scientific theses are not true (and perhaps do not even aim at truth) and are thus not apt to be known through testimony (regardless of whether they are understood). See, e.g., Elgin (2007) for an alternative view of scientific understanding.

${ }^{13}$ Reliable comprehension may itself require a minimal degree of inferential understanding. This will be so if a small amount of inferential understanding is required for concept possession.

${ }^{14}$ As exceptions to this, Goldberg cites McDowell (1981), Ross (1986), Jack (1994), Fricker (2003), and

Goldberg (2004). For more recent work on testimony and linguistic understanding, see Peet (2016, 2019). 
where they stand with respect to the liberal-conservative spectrum. ${ }^{15}$ Having said that, the emphasis in the literature on the importance and abundance of testimonial knowledge (along with the absence of conditions on inferential understanding) suggests that many authors might be committed to a fairly radical Liberalism: it is common for authors to set the scene in papers on testimony by claiming that we gain vast amounts of knowledge through the testimony of others. Here are some examples:

It seems then that testimony is very important in the formation of much that we normally regard as reasonable belief and that our reliance upon it is extensive. Furthermore, this reliance is not limited to the everyday or the merely practical $[\ldots]$ since highly developed theoretical activities are also marked by a reliance upon testimony. (Coady 1994: 7-8)

We humans are essentially social creatures, and it is not clear that we do or could possess any knowledge at all which is not in some way, perhaps obliquely, dependent on testimony. (Fricker 2006: 225)

Testimony is an invaluable source of knowledge. We rely on the reports of those around us for everything from the ingredients in our food and medicine to the identity of our family members, from the history of our civilization to the limits and contents of our planet. If we refrained from accepting what others told us, our lives, both practically and intellectually, would be unrecognizable. (Lackey 2006: 1)

in life as we know it we could not have much knowledge, if indeed we could know anything at all, without relying on what others tell us. (Audi 2013: 507)

\footnotetext{
15 There are authors who claim that, to gain knowledge that $p$ through a speaker's testimony that $p$, the hearer must know that the speaker said that $p$ (e.g., Fricker 1994, 1995, 2003, Malmgren 2006). This might amount to a kind of understanding requirement. However, it is one that, on social externalism, is easily met. Thus, on the assumption of social externalism, this knowledge requirement is compatible with the Liberal View. Fricker (2003) develops a more demanding view of the conditions on knowing what is said and thus may tend towards the conservative end of the spectrum.
} 
Claims such as these are often treated as more or less platitudinous. ${ }^{16}$ Now, it may be that many authors who stress the importance of testimony in this way are concerned only with testimony that is very well understood by hearers. It would still be true that we gain an enormous amount of knowledge through testimony even if the kinds of knowledge so acquired were restricted to things like knowledge about the contents of the fridge, for example (or, indeed, knowledge concerning one's own areas of theoretical expertise). However, I suspect that many authors are more optimistic about the extent of our testimonial knowledge than this, believing, with Goldberg and Adler, that the vast amount of testimonial knowledge that we enjoy includes knowledge - both everyday and theoretical - that we do not well understand. I hope that my argument in this paper will, at the very least, give us reason to think that such claims should not be treated as scene-setting platitudes; and that the Liberal View that underpins them is in need of defence. Against those who endorse it, I will argue that radical versions of the Liberal View are false (although I will concede that the view may apply in some restricted settings). For those readers who are already unsympathetic to the Liberal View, I hope to identify a particular reason for rejecting it that has not yet been recognised in the literature (i.e., Inferential Understanding Dependency). In the next section, I present my argument for Inferential Understanding Dependency. In Sect. 4, I argue that, given Inferential Understanding Dependency, we gain fewer warranted beliefs from testimony than testimonial Liberals would have us believe.

\section{Argument for Inferential Understanding Dependency}

My argument for the relationship between testimonial warrant and linguistic understanding is as follows:

\footnotetext{
${ }^{16}$ Coady's agenda-setting work is an exception to this.
} 
1. If a hearer incompletely understands the content of the speaker's testimony, she will be insensitive to evidence that weighs for or against this content.

2. If a hearer is insensitive to evidence that weighs for or against the testimonial content, her warrant for accepting this testimony will be undermined.

3. Therefore, if a hearer incompletely understands the content of the speaker's testimony, her warrant for accepting this testimony will be undermined.

I defend each of the premises in turn.

\subsection{Premise 1}

Premise 1 states that, if a hearer lacks understanding of the testimonial content, she will be insensitive to evidence that weighs for or against it. To see this, consider the following example.

HIDDEN HORSE. Noa is on a boat which houses a wide variety of animals. She knows what many of the animals are, but others are less familiar to her. Noa carefully makes her way around the boat, noting all of the animals that she sees. After inspecting the boat, Noa forms the following belief:

1) There are no horses on the boat.

Noa then bumps into Zoe. Zoe offers the following reliable testimony:

2) There is a Percheron on the boat.

Noa does not know exactly what a Percheron is, but she is confident that it is a kind of animal. Noa accepts (2) and forms the testimony-based belief that there is a Percheron on the boat. 
In this example, Noa has counterevidence for her testimony-based belief: a Percheron is a kind of horse, and Noa believes (with good reason) that there are no horses on the boat. However, because she doesn't understand the testimonial content very well, she is not sensitive to this counterevidence; had Noa understood the testimonial content better, she would have been better able to discern the evidential support relationships that hold between this testimony and the rest of her beliefs. There are two things to note here. Firstly, my claim at this stage is not that Noa has a defeater for the testimonial content (I discuss this issue below). Rather, the point is merely that her incomplete understanding renders her insensitive to evidence and counterevidence. Secondly, the claim that I am defending concerns the content of the testimony in particular. While one's sensitivity to counterevidence for the testimonial content might depend on linguistic understanding, this is not to say that sensitivity to other kinds of counterevidence is similarly so dependent (although, I will later argue that it is more dependent than one might have thought). For example, if a known liar tells me that $p$, this may be a reason to refrain from accepting $p$ that is independent of $p$ itself.

One might object to HIDDEN HORSE on the grounds that Noa's understanding is too poor to attribute to her the communal concept, PERCHERON. ${ }^{17}$ Thus, she cannot form the testimonybased belief that there is a Percheron on the boat. However, I think most social externalists would allow this as a case of incomplete understanding of a communal concept. Burge (1979), for example, allows that subjects can be attributed a communal concept even when this requires also attributing to them beliefs in conceptual falsehoods (such as 'I have arthritis in my thigh'). Noa is not in the grip of any conceptual error. She even understands that a Percheron is a kind of animal. Thus, her understanding is better in important respects than the understanding of the subjects involved in many of Burge's examples. I think Burge would treat Noa's case as one of agnostic grasp. ${ }^{18}$ To strengthen the case for this classification, we can stipulate that Noa has

\footnotetext{
17 Thank you to an anonymous reviewer for this objection.

${ }^{18}$ For further argument against reinterpretation strategies, see Goldberg (2007: 70ff)
} 
many further true beliefs about Percherons (e.g., that Percherons have four legs, that her cousin owns one, that her cousin's Percheron's name is 'Sherman', that Percherons originate from France, and so on); even with these additional beliefs, she is still significantly insensitive to evidence and counterevidence for the testimonial content.

To recap: What I have argued for so far is that one's ability to recognise counterevidence (or, indeed, supporting evidence) for the content of a piece of testimony is at least heavily dependent on one's grasp of how $p$ relates to one's existing network of beliefs. My hope is that this much is not too controversial. Let's turn to premise 2 .

\subsection{Premise 2}

Premise 2 claims that, if a hearer is insensitive to evidence and counterevidence for a testimonial content, our warrant for accepting the testimony is thereby diminished. What I mean by this is that the degree of warrant that the hearer's testimonial belief enjoys will be lowered; however, I stress that this is compatible with the belief still possessing a level of warrant sufficient for knowledge. At this stage in the paper, my aim is simply to establish a relationship of dependency between warrant and understanding. In Sect. 4, I consider to what extent partial understanding might lower one's degree of warrant to below the threshold for knowledge.

In support of premise 2, first consider HIDDEN HORSE again. In this example, Noa has counterevidence that she us unaware of. Does this affect her warrant for accepting (2) - 'There is a Percheron on the boat'? I think that it is prima facie puzzling what we should say about this case. On the one hand, Noa does have counterevidence for Zoe's testimony: a Percheron is a kind of horse, and so Noa's existing belief ('There are no horses on the boat') contradicts the content of Zoe's testimony. Is this counterevidence a defeater? It might look tempting to say that it is a doxastic defeater. And, if it is, then Noa will lack knowledge-sufficient warrant for accepting Zoe's testimony so long as it remains undefeated. However, on the other hand, Noa 
doesn't realise that her existing belief constitutes counterevidence. Perhaps, then, it does not function as a defeater and, as such, does not undermine her warrant after all.

In fact, I think that neither of these diagnoses is correct. I think that Noa's warrant for accepting the testimony is indeed undermined, but this is not because she possesses a defeater for it. Rather, her warrant is undermined because her insensitivity to evidence and counterevidence renders her an unreliable consumer of testimony. In what follows, I explain why this is so.

\subsubsection{Sensitivity to counterevidence and the reliable consumption of testimony}

As Goldberg (2008) points out, an account of testimonial knowledge acquisition will include constraints on both the speaker's production of testimony and the hearer's consumption of testimony. He writes (considering broadly externalist frameworks):

the acquisition of testimonial knowledge requires both that the testimony consumed be reliable (or fill in your favorite externalist notion here), but also that the hearer herself be a reliable consumer of reliable testimony. (2008: 8)

In HIDDEN HORSE, it is stipulated that the testifier produces reliable testimony. The epistemic problem lies in Noa's consumption of testimony. The problem, I claim, is not that she possesses a defeater. Rather, it is her insensitivity to defeaters for the testimonial content that undermines her warrant for accepting it. Depending on one's view of defeaters, we can understand this insensitivity in different ways. Either Noa can possess doxastic defeaters without realising it or her capacity to possess defeaters itself is undermined (I discuss this option in Sect. 3.2.2). Either way, in cases in which she incompletely understands the testimonial content, her warrant is undermined regardless of whether she possesses counterbeliefs. As such, her warrant would be undermined even if she lacked the counterbelief (1). That is, it would be undermined even in the following modification of the original scenario: 
VISIBLE HORSE. Noa is on a boat which houses a wide variety of animals. She knows what many of the animals are, but others are less familiar to her. Noa carefully makes her way around the boat, noting all of the animals that she sees. After inspecting the boat, and seeing a large horse, Noa forms the following belief:

3) There are horses on the boat.

Noa then bumps into Zoe. Zoe offers the following reliable testimony:

2) There is a Percheron on the boat.

Noa does not know exactly what a Percheron is, but she is confident that it is a kind of animal. Noa accepts (2) and forms the testimony-based belief that there is a Percheron on the boat.

Why should we think that warrant is undermined in VISIBLE HORSE? To form warranted testimonial beliefs, it is not enough that one merely lacks defeaters. Rather, one must exercise a capacity or competency to recognise whether or not one possesses counterevidence for the testimony consumed. This point is made by Pritchard:

...intuitively it is not enough merely to be of the opinion that there are no grounds for doubt - rather one also needs to be competent in forming judgements of this sort. That is, if one were completely incompetent when it comes to assessing whether grounds for doubt are present (one lacks skills for detecting obvious deception, for example), then one could meet this constraint on default epistemic status even though there are manifest grounds for doubt at issue in that situation (perhaps, for example, the testifier 
is making a very serious set of claims whilst dressed in a clown costume and tooting a horn after each statement). (2004: 337)

Pritchard, in this passage, is not considering the role of linguistic understanding in testimonial knowledge acquisition. Rather, he is considering the conditions on warranted testimonial belief more generally. My claim is that incomplete understanding is one factor (perhaps among many) that can undermine or limit one's competence in critically evaluating incoming information. ${ }^{19}$ Pritchard here frames the point as supported by intuition. However, there is further motivation that we could provide from within various different epistemological frameworks. For example, working from within a reliabilist framework, as Goldberg does, we can say that Noa is an unreliable consumer of testimony: she will very easily form false beliefs in cases where she lacks the ability to detect counterevidence for their content (See also Pritchard 2004: 341). As such, even when she does succeed in forming a true belief through accepting poorly understood testimony, this will be down to luck rather than to her exercise of a reliable capacity or employment of a reliable method. Alternatively, one can describe a version of the problem by appeal to the 'monitoring requirement' that is often included in accounts of warranted testimony-based belief formation. Fricker states this requirement as follows:

the hearer must always be monitoring the speaker critically. This is a matter of the actual engagement of a counterfactual sensitivity: it is true throughout of the hearer that if there were any signs of untrustworthiness, she would pick them up. (1994: 154)

Monitoring requirements of one form of another are endorsed by many authors (See, for example, Faulkner 2000, Lackey 2008, Michaelian 2012, Goldberg 2018). ${ }^{20}$ They are arguably

\footnotetext{
${ }^{19}$ As I will explain below, one can think of such a capacity as counterfactually triggered rather than always actively employed (see Fricker 1994).

${ }^{20}$ Since his (2007), Goldberg's views in epistemology have developed. In his (2018), he defends a 'coherence-infused reliabilism' with respect to epistemically proper belief, which combines reliabilist and responsibilist elements. It is worth noting that this later view does not avoid my argument for Inferential Understanding Dependency. Coherence-infused reliabilism includes a minimal monitoring requirement on epistemically proper belief (including testimonial belief). As such, it is vulnerable to my argument for
} 
compatible with many different views of testimonial warrant (Goldberg and Henderson 2006). ${ }^{21}$ Put in terms of monitoring, the problem facing Noa is that, because she does not understand the testimony, her ability to monitor is severely diminished. Agents who do not monitor testimony are gullible consumers of testimony, and this gullibility is incompatible with warranted testimony-based belief formation. ${ }^{22}$

I have just argued that Noa's warrant for accepting testimony will be undermined when she is insensitive to counterevidence because a capacity to detect counterevidence is in various frameworks taken to be required for reliable consumption of testimony. And, as premise 1 claims, any case in which the hearer poorly understands the testimony she consumes will be a case in which her sensitivity to counterevidence is undermined to some degree. I think it is useful to compare the present problem concerning linguistic understanding to a structurally similar challenge that arises in the debate concerning the testimony-based beliefs of infants and young children. In making this comparison, I do not intend to commit to any particular analysis of, or solution to, the latter challenge. Rather, I think that consideration of the reasons that have been offered for thinking that young children might lack warranted testimony-based beliefs will help us to see why poor linguistic understanding undermines testimonial warrant for adults like Noa.

\subsubsection{Children's consumption of testimony}

Many authors accept that, before a certain age at least, young children are relatively poor at evaluating the testimony they consume. This is taken to present a serious challenge to reductionist views of testimonial warrant, as these views require that agents possess fairly

the reasons given here: effective monitoring requires (inferential) understanding of the testimonial content. As I go on to argue in Sect. 4, this means that, like any theory of testimony that maintains a monitoring requirement, it ought to reject the Liberal View.

${ }^{21}$ For criticisms of monitoring requirements, see Shieber (2012).

${ }^{22}$ This gullibility might be ultimately cashed out in terms of unreliability. However, it might be understood in alternative terms, such as epistemic irresponsibility or irrationality. For discussion of various ways to understand gullibility, see Goldberg and Henderson (2006). 
sophisticated critical reasoning skills in order to form warranted testimony-based beliefs. Some authors have suggested, however, that a version of the same problem will face anti-reductionist views as well. Lackey (2005) argues that the objection to reductionism relies on accepting the claim that infants and young children are outside the space of reasons and, as such, will be incapable of substantively satisfying the anti-reductionist's No Defeaters condition on testimonial knowledge.

There are responses to Lackey's argument in the literature. ${ }^{23}$ Goldberg (2008) argues that, even if children are insensitive to counterevidence, the adults in a child's environment can satisfy the No Defeaters condition (substantively) on their behalf, thus rendering them reliable consumers of testimony after all. Alternatively, Graham (2016) argues that Lackey misrepresents the initial objection to reductionism: the objection requires only that young children lack critical reasoning skills; it does not require that children are outside the space of reasons altogether; thus, they may be adequately sensitive to counterevidence such that anti-reductionism is not threatened. Graham and Goldberg may be right about the anti-reductionist's prospects here; however, neither denies the conditional claim that if young children are incapable of recognising counterevidence for the testimony they consume, then their ability to form warranted testimonial beliefs is undermined (at least when considered in isolation from their social environment). Many authors accept this conditional for precisely this reason: agents need to be competent in assessing incoming information - it is not enough that they merely lack reasons for doubt, for the lacking of such reasons might be due to incompetence or some other obstacle to reflection.

Lackey makes this point as follows. Supposing that young children cannot appreciate counterevidence then, even if they can possess counterbeliefs, these cannot amount to doxastic

\footnotetext{
${ }^{23}$ For further accounts of young children's testimony-based beliefs, see Fricker (1995), Van Cleve (2006), Audi (1997).
} 
defeaters (2005: 178ff). ${ }^{24}$ This is because, to be a genuine doxastic defeater, it must be correct for us to describe the agent who possesses the defeater as irrational if she should maintain the defeated belief. This attribution of irrationality, Lackey emphasises, is normative - we are saying that subjects should receive a negative epistemic evaluation because they are failing to do what rationality requires. Infants, however, (to the extent that they are insensitive to reasons or evidence) are outside the bounds of rationality. We cannot say that they should give up their beliefs in the face of conflicting evidence because they are incapable of doing this. Thus, Lackey marks a distinction between counterbeliefs and doxastic defeaters. She writes:

While the former [counterbeliefs] are merely beliefs, the content of which conflicts with an already held belief, the latter [doxastic defeaters] are counterbeliefs which contribute epistemic irrationality to an agent's doxastic corpus. Otherwise put, to say that an agent has a counterbelief is a descriptive statement while saying that an agent has a doxastic defeater is a normatively loaded evaluation. Given this distinction, if infants and young children cannot have reasons for their beliefs, then, even if they can have counterbeliefs, they are incapable of having doxastic defeaters. (2005: 179)

For Lackey, then, it's not just that young children would lack defeaters: they would be incapable of possessing them. For this reason, Lackey explains, they would satisfy a No Defeaters condition only trivially: they possess no defeaters only because they are incapable of doing so, not because of the successful exercise of a competency (2005: 168). Lackey thinks that any plausible version of the No Defeaters Condition will require substantive satisfaction. The way that she motivates this claim echoes the passage from Pritchard above. If mere trivial satisfaction of the No Defeaters Condition is permitted, then we would have to allow that an agent can warrantedly accept any reliable report whatsoever, no matter how much counterevidence is presented to her. This, Lackey says, would be absurd; but, moreover, it is in

\footnotetext{
${ }^{24}$ Lackey's aim in that paper is to defend reductionism from the objection that it entails that young children cannot gain knowledge through testimony. Lackey does not actually endorse reductionism; but she does think that this objection is not a reason to reject the view in favour of anti-reductionism.
} 
tension with the anti-reductionist's reason for endorsing a No Defeaters Condition in the first place: anti-reductionists employ such a condition on warranted belief formation precisely to rule out cases in which an agent accepts testimony in the face of counterevidence. ${ }^{25}$ Thus, young children - if they are indeed unable to recognise counterevidence - cannot form warranted testimonial beliefs.

Pritchard expresses a similar position regarding the testimonial beliefs of young children. $\mathrm{He}$ suggests that their inability to competently evaluate defeaters will undermine the reliability of their consumption of testimony:

[Young children] will lack the competency in evaluating testimony (and, relatedly, defeaters) that comes with repeated exposure to instances of testimony within a social milieu, and this is bound to undermine their reliability in forming TBBs [testimonybased beliefs]. At best, then, all we will be able to say about the TBBs formed by agents in this stage is that these agents are epistemically blameless in holding them, not that they are justified in holding them, whether by the lights of an externalist or an internalist account of testimonial justification. (2004: 341)

In the debate concerning young children's consumption of testimony, then, an inability to appreciate counterevidence is taken to undermine testimonial warrant. As mentioned above, various authors have defended anti-reductionism from Lackey's argument. However, even if Lackey's argument fails against anti-reductionism, I think that the considerations that she raises $d o$ apply to adult consumers of testimony like Noa. For the case of young children, the issue is not (or not primarily) that children do not understand the testimony they consume. Rather, the claim is that they are cognitively immature, and this is what renders them incapable of appreciating counterevidence. Noa, in contrast, has the cognitive maturity to recognise

\footnotetext{
${ }^{25}$ While Lackey focuses on the special reasons that anti-reductionists have to endorse the No Defeaters Condition, reductionists will have similar sorts of reasons.
} 
counterevidence, but her ability to do so is compromised in cases where she lacks linguistic understanding of the testimonial content. Interestingly, whereas, as Pritchard suggests, we might describe young children as epistemically blameless, Noa does not seem to deserve exculpation. A child might be doing the best she can, given her cognitive capacities, but Noa is not. Noa, then, is, epistemically speaking, even worse off than a young child. She is not merely an unreliable consumer of testimony, but an epistemically blameworthy one at that.

To recap: when subjects fail to understand a testimonial content, they will be insensitive to evidence and counterevidence for that content. To the degree that they are insensitive in this way, their capacity to recognise (or, perhaps, possess) defeaters is undermined. To the extent that this capacity is undermined, their testimonial warrant will be similarly undermined - for example, because the agent is rendered an unreliable consumer of testimony. Thus, we should say that, to the extent that subjects like Noa incompletely understand a testimonial content, their warrant for accepting this content will be undermined. What this means is that, even in cases in which a subject in fact possesses no counterbeliefs, her warrant may be undermined merely in virtue of her incomplete understanding. This, I claim, is what is going on in VISIBLE HORSE. What matters for testimonial warrant is not merely whether you possess counterbeliefs, but whether you have the capacity to recognise the evidential support relationships that hold between the testimonial content and the rest of your beliefs (whatever these may be).

\section{$4 \quad$ Against the Liberal View}

Thus far, I have made a case for the claim that testimonial warrant depends upon (inferential) linguistic understanding. However, I have not yet shown that incomplete understanding will often lower warrant to below the threshold for knowledge. In this final section, I will argue that often, an individual's testimonial belief will lack knowledge-sufficient warrant unless it is reasonably well understood. If this is true, the Liberal View is false. 
In the preceding, my argument has focused on Noa's ability to monitor the content of testimony (where such monitoring might amount to a counterfactual sensitivity to counterevidence rather than an active vetting procedure); but monitoring of content is not the only kind of monitoring that might be involved in a testimonial exchange. Hearers can monitor speakers for signs of trustworthiness, they can monitor the testimony for prior plausibility, they can assess whether the speaker is a relevant authority, and so on. Those committed to the Liberal View might try to claim that, if the hearer has the ability to monitor testimony along these various additional dimensions, it will not matter if her understanding of the testimony is poor - these additional sources of evidence may counterbalance any warrant lost to incomplete understanding. In what follows, I will argue that, in some cases perhaps, these additional varieties of monitoring may indeed have this warrant-boosting effect. However, the contexts in which this occurs will be limited and, as such, a large class of contexts will be such that a relatively high degree of inferential understanding is required for testimonial knowledge acquisition.

To begin with, consider what we would say about Noa if her only available method of monitoring testimony was the sort of content-monitoring that has been under discussion. That is, we are imagining that Noa has no information about the speaker whatsoever - she does not even know whether the apparent testimony she consumes was produced by a sentient being. I think, under these (rather artificial) circumstances, it is plausible to say that Noa's testimonial belief would lack knowledge-sufficient warrant. Accepting testimony that you do not understand, from speakers about whom you know nothing, seems like a bad belief-forming policy: Noa could very easily form false testimonial beliefs using this method. The Liberal View, of course, need not claim that testimonial beliefs are warranted under such circumstances. Rather, I present this case to support the thought that, without some further source of warrant, our poorly understood testimonial beliefs will not amount to knowledge. The question we need to answer now, then, is whether additional varieties of testimonial monitoring might counteract warrant lost to incomplete understanding. I will argue that many of these varieties of monitoring are themselves reliant on content-monitoring and, as such, linguistic understanding is more often 
required for testimonial knowledge acquisition than those committed to the Liberal View have realised.

Let's consider monitoring for prior plausibility first. This kind of monitoring we can easily rule out as of any help to the Liberal View: a hearer will not be in a position to assess the plausibility of the testimony to the extent that she fails to understands its content. For example, if all you know about a Percheron is that it is a kind of animal, it is not possible to judge the plausibility of the claim that there is one on your boat - it could be kind of elephant, a blue whale, or even some fictional Lovecraftian horror for all you know. Partial understanding the testimonial content severs your ability to assess this content from an immensely rich archive of background beliefs and theory that would normally guide your testimonial belief forming process or underwrite your counterfactual sensitivity to reasons to reject the testimony. ${ }^{26}$

In contrast to monitoring for plausibility, there is one kind of monitoring that appears to be largely independent of the testimonial content: monitoring for physical signs of trustworthiness. For example, perhaps the speaker looks or sounds unsure, or dishonest somehow. This source of evidence, then, is one that a hearer can rely on without linguistic understanding. However, it would be implausible to think that this alone is enough to offset warrant undermined by partial understanding. Speakers do not often exhibit very obvious signs of insincerity ${ }^{27}-$ and, as just explained, hearers who lack understanding will be unable to rely on an assessment of the plausibility of the testimonial content to inform their assessment of the speaker's sincerity. Moreover, many speakers will be highly sincere and yet mistaken or unreliable, exhibiting little indication of their testimony's defects. As such, while an ability to monitor for physical signs of trustworthiness may be a source of warrant for a hearer's testimony-based belief, it is unlikely that it will often provide warrant sufficient to counteract partial understanding.

\footnotetext{
${ }^{26}$ The sorts of resources available to the hearer are discussed in Kenyon (2013) and Fricker (1994).

${ }^{27}$ As Shieber (2012) argues, the literature in social psychology suggests both that there may be no uniform signs of untrustworthiness and that, if there are, subjects are not good at picking up on them.
} 
What about monitoring for the expertise or authority of the speaker ${ }^{28}$ Imagine, for example, that you are talking to a medical researcher, and she tells you that coeliac sprue is an autoimmune disease. Surely, we might think, we can trust this expert with respect to some statement in her domain of expertise. However, things are not as simple as this. For how is a hearer to ascertain that this statement does indeed fall within the speaker's domain of expertise without some understanding of the content of the utterance? Those who have medical expertise do not have all-encompassing medical expertise. Rather, experts are typically specialists. One can have expertise in cardiology, for example, while having little knowledge of autoimmune diseases (or of coeliac disease in particular). The point is that, without some (fairly sophisticated) linguistic understanding, one is not in a position to competently judge whether the speaker is a relevant expert or authority. Is this always the case? Might there be some epistemic environments in which we do not require linguistic understanding to identify relevant experts (or reliable testifiers)? There may be some such environments: when it comes to certified authorities, there is strong reason to trust their testimony on certain topics. The medical context might yet provide an example of this. Imagine that you are in your doctor's office and she informs you that coeliac sprue is an autoimmune disease. Here it is more plausible that your resultant testimony-based belief is warranted (assuming the case is otherwise a 'happy' one). If one is in a position to monitor for the certified expertise of the speaker, then, this might constitute a special kind of epistemically friendly environment - one in which only certain matters are likely to be discussed and in which, with respect to these matters, you are very unlikely to be misled by the speaker. This last kind of monitoring then - monitoring for certified authorities that you can recognise as such - might be a kind for which any warrant lost to partial understanding is sufficiently counterbalanced to yield testimonial knowledge. ${ }^{29}$ However, we are rarely in this kind of environment. This means that, although the Liberal View may be true with respect to these exceptional circumstances, it will not be true for a significant proportion of

\footnotetext{
${ }^{28}$ For accounts of epistemic expertise and authority, respectively, see Croce (2019) and Zagzebski (2012). ${ }^{29}$ This may not be the only kind of warrant-boosting environment. Perhaps there are methods that we can employ to identify experts (Goldman 2001). Alternatively, Goldberg's (2008) approach to children's consumption of testimony may offer an example of a different kind of warrant-boosting context (although his approach cannot be extended to adults' consumption of testimony).
} 
our testimonial exchanges. Even when varieties of testimonial monitoring do not concern the testimonial content directly, their effectiveness is very often indirectly dependent on our ability to understand this content, and thus we are rarely absolved of the epistemic responsibility to (inferentially) understand what others are telling us.

\section{Conclusion}

I have argued that, if a hearer lacks (inferential) understanding of the testimonial content, her warrant for accepting a speaker's testimony will be undermined. I motivated this view, Inferential Understanding Dependency, by arguing that poor understanding undermines one's ability to recognise evidence and counterevidence and this, in turn, undermines testimonial warrant. Having established a relationship between understanding and warrant, I went on to consider whether this might pose a threat to the Liberal View of testimony. Testimonial Liberals are committed to the claim that no more than a minimal degree of inferential understanding is required for testimonial knowledge acquisition. I argued that, on the contrary, while there may be some epistemically friendly environments in which little inferential understanding is required, a significant proportion of testimonial exchanges will require that we understand our interlocutor reasonably well.

My conclusion is somewhat sceptical: we have less testimonial knowledge than Liberals would have us believe. I would like to note two things about the consequences of my argument in closing. The first is practical. The sceptical thesis that I argue for has an obvious remedy: if we want to gain knowledge through testimony, we should work to understand each other better. The second consequence concerns the testimony literature. As noted earlier, it is typically assumed that we gain a great deal of knowledge through testimony. Due to the prevalence of this assumption, it has been treated as a constraint on a good theory of testimony (one that itself places constraints on a theory of linguistic understanding) that it can claim that testimonial knowledge is easily and often acquired. This constraint has served to stack the deck against 
views in the epistemology of testimony - like reductionism - that are thought to be committed to more demanding conditions on testimonial knowledge acquisition. I hope to have offered good reason to think that, rather than helping ourselves to such a constraint as a presumption of the debate, we should more carefully examine our commitment to it, and seriously consider what an epistemology of testimony might look like without it.

\section{Bibliography}

Adler, J. 1996. Transmitting knowledge. Noûs, 30: 99-111.

Audi, R., 1997. The place of testimony in the fabric of knowledge and justification. American Philosophical Quarterly, 34: 405-422.

Audi, R., 2013. Testimony as a social foundation of knowledge. Philosophy and Phenomenological Research, 87: 50-531.

Bergmann, M. 2005. Defeaters and higher-level requirements. The Philosophical Quarterly, 55: 419-436.

Brown, J. 2004. Anti-individualism and knowledge, MIT Press.

Burge, T., 1979. Individualism and the mental. Midwest Studies in Philosophy, 4: 73-121.

Burge, T., 1993. Content preservation. The Philosophical Review, 102: 457-488.

Burge, T. 2003. Perceptual entitlement. Philosophy and Phenomenological Research, 67: 503548.

Coady, C.A.J. 1992. Testimony: A Philosophical Study. Oxford: Clarendon Press.

Croce, M. 2019. On what it takes to be an expert. The Philosophical Quarterly, 69: 1-21.

Elgin, C. 2007. Understanding the facts? Philosophical Studies, 132: 33-42.

Fricker, E. 1995. Telling and trusting: Reductionism and anti-reductionism in the epistemology of testimony. Mind, 104: 393-411.

Fricker, E. 2003. 'Understanding and knowledge of what is said. In A. Barber (ed.) The Epistemology of Language, Oxford: Oxford University Press.

Fricker, E. 2006. Testimony and epistemic autonomy. In J. Lackey and E. Sosa (eds.), The epistemology of testimony. Oxford: Oxford University Press. 
Fricker, E. 2012. Stating and insinuating. Proceedings of the Aristotelian Society, Supplementary Volumes, 86: 61-94.

Gerken, M. 2013. Internalism and externalism in the epistemology of testimony. Philosophy and Phenomenological Research, 87: 532-557.

Goldberg, S. 2004. Radical interpretation, understanding, and testimonial transmission. Synthese, 138: 387-416.

Goldberg, S. 2007. Anti-individualism: Mind and language, knowledge and justification. Cambridge: Cambridge University Press.

Goldberg, S. 2008. Testimonial knowledge in early childhood, revisited. Philosophy and Phenomenological Research, 76: 1-36.

Goldberg, S. 2018. To the best of our knowledge. Oxford: Oxford University Press.

Goldberg, S. and Henderson, D. 2006. Monitoring and anti-reductionism in the epistemology of testimony. Philosophy and Phenomenological Research, 72: 600-617.

Goldman, A. 1999. Knowledge in a social world. Oxford: Clarendon Press.

Goldman, A. 2001. Experts: Which one should you trust? Philosophy and Phenomenological Research, 63: 85-110.

Graham, P. (2016). Formulating reductionism about testimonial warrant and the challenge from childhood testimony. Synthese, SI: Defeaters in Current Epistemology, 1-21.

Jack, J. 1994. The role of comprehension. In B. K. Matilal and A. Chakrabarti (eds.) Knowing from words, Amsterdam: Kluwer Academic Publishers.

Kenyon, T. 2013. The informational richness of testimonial contexts. The Philosophical Quarterly, 63: 58-80.

Lackey, J. 2005, Testimony and the infant/child objection. Philosophical Studies, 126: 163-90.

Longworth, G. (2010). A plea for understanding. In S. Sawyer (ed.), New Waves in Philosophy of Language, Basingstoke: Palgrave Macmillan.

Malmgren, A. 2006. Is there a priori knowledge by testimony? Philosophical Review, 115: 199241. 
McDowell, J. 1981. Anti-realism and the epistemology of understanding. Reprinted in McDowell, 1998, Meaning, knowledge, and reality, Cambridge: Harvard University Press.

Peet, A. 2016. Testimony and the epistemic uncertainty of interpretation. Philosophical Studies, 173: pp 395-416.

Peet, A. 2018. Testimonial knowledge without knowledge of what is said. Pacific Philosophical Quarterly, 99: 65-81.

Peet, A. 2019. Knowledge-yielding communication. Philosophical Studies, 176: 3303-3327.

Pollock, J. 1986. Contemporary theories of knowledge. Savage, MD: Rowman and Littlefield.

Pritchard, P. 2004. The epistemology of testimony. Philosophical Issues, 14: 326-348.

Ross, A. 1986. Why do we believe what we are told? Ratio, 28, 69-88.

Shieber, J. 2012. Against credibility. Australasian Journal of Philosophy, 90: 1-18.

Shogenji, T. 2006. A defense of reductionism about testimonial justification of beliefs. Noûs, 40: $331-346$.

Weiner, M. 2003. Accepting testimony. The Philosophical Quarterly, 53: 256-64.

Van Cleve, J. 2006. Reid on the credit of human testimony. In J. Lackey \& E. Sosa (Eds.), The epistemology of testimony. Oxford: Oxford University Press.

Zagzebski, L. 2012. Epistemic authority: A theory of trust, authority, and autonomy in belief. Oxford: Oxford University Press. 